\title{
BMJ Open Incremental predictive value of screening for anxiety and depression beyond current type 2 diabetes risk models: a prospective cohort study
}

\author{
Evan Atlantis, ${ }^{1,2,3}$ Shima Ghassem Pour, ${ }^{3,4}$ Federico Girosi ${ }^{3,4}$
}

To cite: Atlantis E, Ghassem Pour S, Girosi F. Incremental predictive value of screening for anxiety and depression beyond current type 2 diabetes risk models: a prospective cohort study. BMJ Open 2018;8:e018255. doi:10.1136/ bmjopen-2017-018255

- Prepublication history for this paper is available online To view these files, please visit the journal online (http://dx.doi. org/10.1136/bmjopen-2017018255).

Received 21 June 2017 Revised 13 October 2017 Accepted 13 December 2017

Check for updates

${ }^{1}$ School of Nursing and Midwifery, Western Sydney University, Sydney, New South Wales, Australia

${ }^{2}$ School of Medicine, University of Adelaide, Adelaide, South Australia, Australia

${ }^{3}$ Capital Markets CRC, Sydney, New South Wales, Australia ${ }^{4}$ Translation Health Research Institute, Western Sydney University, Kingswood, New South Wales, Australia

Correspondence to Dr Evan Atlantis; E.Atlantis@westernsydney. edu.au

\section{ABSTRACT}

Objectives We sought to determine whether screening for anxiety and depression, an emerging risk factor for type 2 diabetes (T2D), adds clinically meaningful information beyond current T2D risk assessment tools.

Design Prospective cohort.

Participants and setting The 45 and Up Study is a large-scale prospective cohort of men and women aged 45 years and over, randomly sampled from the general population of New South Wales, Australia. 51588 participants without self-reported diabetes at baseline (2006-2009) were followed up for approximately 3 years (2010).

Methods T2D status was determined by self-reported doctor who diagnosed diabetes after the age of 30 years, and/or current use of metformin. Current symptoms of anxiety and/or depression were measured by the 10-item Kessler Psychological Distress Scale (K10). We determined the optimal cut-off point for K10 for predicting T2D using Tjur's R2 and tested risk models with and without the K10 using logistic regression. We assessed performance measures for the incremental value of the K10 using the area under the receiver operating characteristic (AROC), net reclassification improvement (NRI) and net benefit (NB) decision analytics with sensitivity analyses.

Results T2D developed in 1076 individuals ( $52.4 \%$ men). A K10 score of $\geq 19$ (prevalence $8.97 \%$ ), adjusted for age and gender, was optimal for predicting incident T2D (sensitivity $77 \%$, specificity $53 \%$ and positive predictive value $3 \%$; OR 1.70 (95\% Cl 1.41 to $2.03, \mathrm{P}<0.001)$. K10 score predicted incident T2D independent of current risk models, but did not improve corresponding AROC, NRI and NB statistics. Sensitivity analyses showed that this was partially explained by the baseline model and the small effect size of the K10 that was similar compared with other risk factors.

Conclusions Anxiety and depressing screening with the $\mathrm{K} 10$ adds no meaningful incremental value in addition to current T2D risk assessments. The clinical importance of anxiety and depression screening in preventing T2D requires ongoing consideration.

\section{INTRODUCTION}

Type 2 diabetes (T2D) is the most common type of diabetes and accounts for at least $90 \%$ of all cases. ${ }^{1}$ The Global Burden of Disease

\section{Strengths and limitations of this study}

- We considered various approaches beyond statistical analyses to assess the incremental predictive value of screening for anxiety and depression to current type 2 diabetes (T2D) risk models.

- We determined the optimal cut-off point on the K10 for predicting T2D risk.

- Other strengths of this study include the recruitment of a large (over 250000 participants) populationbased sample at baseline, and the high (over 60\%) response rate achieved in the subsample at followup.

- Study weaknesses include the low incidence of T2D observed in the cohort, reliance on self-report measures, low (less than 18\%) response rate achieved at baseline, residual confounding and misclassification of variables potentially resulting in bias.

Study ranked diabetes the 14th leading cause of global disease burden in 2010, moving up several places since $1990 .^{2}$ This trend is likely to continue increasing in coming decades since it is estimated that over 415 million people worldwide have diabetes, and by 2040 this figure is projected to rise to 642 million. ${ }^{1}$ Effective prevention of T2D is urgently needed in high-income countries, where healthcare expenditure for diabetes is among the highest in the world, ${ }^{1}$ to realise significant population health and economic benefits. ${ }^{3}$

People with diagnosed T2D are likely to have progressed from an intermediate stage of hyperglycaemia called 'prediabetes'. Prediabetes is defined as impaired fasting glucose and/or impaired glucose tolerance. ${ }^{4}$ It is estimated that the prevalence of pre-diabetes may have reached 20\%-30\% in high-income countries such as Australia and the USA. ${ }^{56}$ Hyperglycaemia and consequent progression to T2D is partially explained by sociodemographics ${ }^{7}$ as well as obesity and lifestyle risk factors. ${ }^{8-11}$ Thus, diabetes prevention 
programmes targeting high-risk individuals could effectively delay their progression from prediabetes to diagnosed T2D.

Indeed, national ${ }^{12}$ and international ${ }^{11}$ guidelines recommend lifestyle intervention that focuses on achieving a healthy body weight for the primary prevention of T2D, based on large randomised controlled trials (RCTs) in people with prediabetes. ${ }^{13}$ However, diabetes is a chronic physical health condition that is often comorbid with clinically relevant symptoms of depression and anxiety. ${ }^{14-16}$ Comorbid mental disorders worsen the self-care, ${ }^{17}$ health ${ }^{18-20}$ and economic burden of diabetes, ${ }^{21}$ and predict non-completion of exercise-based intervention. ${ }^{22}{ }^{23}$ Similarly, depression, anxiety and eating disorders are often present in people with diabetes and obesity $(40 \%-70 \%),{ }^{24-28}$ which adversely affects weight loss, ${ }^{29-31}$ sleep quality, ${ }^{32}$ health-related quality of life and health service use. ${ }^{33}$ Therefore, people with depression and anxiety present with barriers to weight loss and sustainable healthy lifestyle changes (especially diet and exercise behaviours); this suggests that preventing T2D in this high-risk population group would be challenging.

Observational studies show that clinically significant depression (defined by diagnostic criteria or elevated number and/or severity of depressive symptoms) is consistently associated with a twofold increased risk of diabetes. ${ }^{34-36}$ More recently, we showed that having a current depressive and/or anxiety disorder more than doubles the risk of developing diabetes over 2 years in a large cohort study, the Netherlands Study of Depression and Anxiety. ${ }^{37}$ Thus, having current symptoms of anxiety and/or depression could be a novel risk factor for T2D in addition to being a major barrier to achieving sustained healthy lifestyle changes (especially diet and exercise behaviours).

Effective prevention of T2D requires early identification of high-risk individuals who might benefit from targeted intervention. ${ }^{38}$ There is evidence suggesting that screening for T2D risk factors is cost-effective in high-risk individuals and with appropriate intervention. ${ }^{39}$ There are several diabetes risk models or scoring systems (often called 'risk assessment tools') with potential adaptation for use in routine clinical practice. ${ }^{40}$ Variants of these T2D risk tests are currently used in national diabetes prevention programmes worldwide, and typically include questions on demographics (age, gender, ethnicity), medical history (self and family), body weight and waist circumference, lifestyle (physical inactivity, diet) and pathology results (eg, glucose, triglycerides). However, these diabetes risk models may need to be updated as novel risk factors have since emerged. Therefore, the aim of this study was to determine whether screening for anxiety and/or depression adds clinically meaningful information beyond current T2D risk models, to inform guidelines, consumers and clinical practice.

\section{METHODS}

\section{Study design and setting}

The 45 and Up Study is a large prospective cohort study of men and women aged 45 years and older from the general population of New South Wales (NSW), Australia. ${ }^{41}$ Participants were randomly sampled from the Medicare Australia enrolment database held by the Department for Human Services. Eligible individuals were invited to participate by mail, which included participant information, study questionnaire, consent form and a reply paid envelope. Recruitment into the 45 and Up Study was from 2006 through 2009, and had an overall response rate of $18 \%$, comprising approximately $11 \%$ of target population. Although the response rate was low and participants from favourable socioeconomic groups (more people in the highest household income group) were likely to enrol, previous work has shown that findings based on internal comparisons for estimates of exposure-outcome relationships, such as ORs, are generalisable and comparable to those derived from the NSW Population Health Survey. ${ }^{42}$ Also, the 45 and Up cohort was generally healthier: the prevalence of smoking, high/very high psychological distress, ever diagnosed with hypertension, diabetes and asthma was lower than participants in the NSW Population Health Survey.

The Social, Economic and Environmental Factors (SEEF) study was conducted in 2010 as the first follow-up of a subsample of the 45 and Up Study. The SEEF questionnaire, which extended the original 45 and Up Study questionnaire, was distributed to the first 100000 of the 45 and Up Study participants, of whom 60404 returned completed questionnaires yielding a response rate of $60.4 \%$. After excluding baseline participants with known diabetes $(n=4653)$, and incomplete data for one or more of the following variables: body mass index (BMI; $\mathrm{n}=3395)$, K10 score $(\mathrm{n}=1343)$ and country of birth $(\mathrm{n}=575)$, the final cohort sample studied consisted of 51588 participants.

\section{Primary endpoint}

Diabetes at baseline and follow-up was defined by self-reported medically diagnosed diabetes, and use of metformin (diabex, diaformin) in the baseline and follow-up questionnaire. ${ }^{43}$

\section{Predictor variables}

As done previously, ${ }^{38}$ we selected predictor variables from risk models that could be used in routine clinical practice including the Australian type 2 diabetes risk assessment tool (AUSDRISK) ${ }^{44}$ Atherosclerosis Risk in Communities, ${ }^{45}$ Cambridge risk score,${ }^{46}$ Finnish Diabetes Risk Score (FINDRISC) ${ }_{1}^{47}$ Framingham Offspring Study ${ }^{48}$ San Antonio Heart Study ${ }^{49}$ and QDScore.$^{50}$ All risk factor variables were collected through a self-administered questionnaire from the 45 and Up Study Baseline Questionnaire. ${ }^{51}$ Risk factors included age, gender and country of birth (other vs Australian born); family history of diabetes (for blood relatives only); current medications identified for high blood pressure (Avapro, 
Table 1 Baseline characteristics of participants in the SEEF subsample of the 45 and Up study cohort by T2D status at follow-up, including crude incidence and corresponding unadjusted ORs

No T2D ( $n=49859) \quad$ Incident T2D ( $n=1067) \quad \%$ with T2D Unadjusted OR $(95 \% \mathrm{Cl})$

\begin{tabular}{|c|c|c|c|c|}
\hline \multicolumn{5}{|l|}{ Age (years) } \\
\hline $45-54$ & 17387 & 241 & 1.37 & 1 \\
\hline $55-64$ & 16518 & 359 & 2.13 & 1.49 (1.26 to 1.76$)$ \\
\hline 65 and over & 17047 & 492 & 2.8 & 2.13 (1.80 to 2.52 ) \\
\hline \multicolumn{5}{|l|}{ Gender } \\
\hline Female & 28181 & 521 & 1.81 & 1 \\
\hline Male & 22771 & 571 & 2.45 & 1.27 (1.12 to 1.44$)$ \\
\hline \multicolumn{5}{|l|}{ Australian born } \\
\hline Yes & 39627 & 832 & 2.19 & 1 \\
\hline No & 10885 & 244 & 2.05 & 1.12 (0.96 to 1.29$)$ \\
\hline \multicolumn{5}{|c|}{$\begin{array}{l}\text { Family history of diabetes (blood } \\
\text { relatives only) }\end{array}$} \\
\hline No & 40806 & 747 & 1.80 & 1 \\
\hline Yes & 10146 & 345 & 3.29 & 1.83 (1.60 to 2.09 ) \\
\hline
\end{tabular}

Currently taking antihypertensive medications

\begin{tabular}{|c|c|c|c|c|}
\hline No & 40765 & 729 & 1.76 & 1 \\
\hline Yes & 10187 & 363 & 3.44 & 1.47 (1.28 to 1.68$)$ \\
\hline \multicolumn{5}{|l|}{ Current smoker } \\
\hline No & 48171 & 1013 & 2.05 & 1 \\
\hline Yes & 2781 & 79 & 2.76 & 1.61 (1.25 to 2.03$)$ \\
\hline \multicolumn{5}{|l|}{ Insufficient physical activity } \\
\hline No ( $\geq 150 \mathrm{~min} /$ week) & 42669 & 861 & 1.97 & 1 \\
\hline Yes (<150 min/week) & 8283 & 231 & 2.71 & 0.85 (0.74 to 1.00$)$ \\
\hline \multicolumn{5}{|c|}{$\begin{array}{l}\text { Usually eat vegetables or fruit serves } \\
\text { daily }\end{array}$} \\
\hline No & 19742 & 447 & 2.21 & 1 \\
\hline Yes & 31210 & 645 & 2.02 & 0.98 (0.86 to 1.12$)$ \\
\hline \multicolumn{5}{|l|}{ Body mass index class $\left(\mathrm{kg} / \mathrm{m}^{2}\right)$} \\
\hline Underweight (<18.50) & 660 & 9 & 1.34 & 1.18 (0.56 to 2.18$)$ \\
\hline Healthy weight (18.50-24.99) & 20896 & 229 & 1.11 & 1 \\
\hline Overweight (25.00-29.99) & 20243 & 421 & 2.03 & 1.70 (1.45 to 2.01$)$ \\
\hline Obese $(\geq 30.00)$ & 9153 & 427 & 4.45 & 3.80 (3.22 to 4.50$)$ \\
\hline \multicolumn{5}{|l|}{ Psychological distress } \\
\hline No (K10 score<19) & 46411 & 951 & 3.01 & 1 \\
\hline Yes (K10 score $\geq 19)$ & 4541 & 141 & 2.01 & 1.48 (1.22 to 1.78$)$ \\
\hline
\end{tabular}

SEEF, Social, Economic and Environmental Factors; T2D, type 2 diabetes

Karvea, Coversyl, Coversyl Plus, Micardis, Norvasc, Tritace); current regular smoker; insufficient daily serves of vegetables or fruit (none) and physical inactivity (less than $150 \mathrm{~min}$ in last week); and overweight and obesity based on BMI computed as weight in kilograms divided by height in metres squared. Standard international cut-off points were used to define underweight $\left(\mathrm{BMI}<18.50 \mathrm{~kg} / \mathrm{m}^{2}\right)$, healthy weight (BMI $18.50-24.99 \mathrm{~kg} / \mathrm{m}^{2}$ ), overweight (BMI $25.00-29.99 \mathrm{~kg}$ / $\left.\mathrm{m}^{2}\right)$ and obesity $\left(\mathrm{BMI} \geq 30.00 \mathrm{~kg} / \mathrm{m}^{2}\right)$ categories.
Current symptoms of anxiety and depression were measured with the 10-item Kessler Psychological Distress Scale (K10), which was developed to monitor population prevalence and trends in non-specific psychological distress. ${ }^{52}$ The K10 has been shown to accurately predict probable current anxiety and affective disorders according to the Composite International Diagnostic Interview, which corresponds to definitions and criteria of the Diagnostic and Statistical Manual of Mental Disorders 
Table 2 Beta coefficients for risk factors from two logistic regression models, without (model 1 ) and with (model 2 ) the K10 binary variable

\begin{tabular}{ll}
\hline Variables (exposure category) & Estimate $(95 \%$ Cl) \\
\hline Model 1: without K10 & \\
\hline Age (55-65 years) & $0.38(0.20$ to 0.54$)$ \\
\hline Age (65years and over) & $0.72(0.55$ to 0.88$)$ \\
\hline Gender (male) & $0.23(0.11$ to 0.36$)$ \\
\hline BMI (underweight) & $0.18(-0.55$ to 0.80$)$ \\
BMI (overweight) & $0.54(0.37$ to 0.70$)$ \\
BMI (obese) & $1.35(1.18$ to 1.51$)$ \\
\hline Smoking status (smoker) & $0.51(0.28$ to 0.76$)$ \\
\hline Hypertensive medications (yes) & $0.38(0.25$ to 0.52$)$ \\
\hline Diabetes history (yes) & $0.61(0.47$ to 0.74$)$ \\
Australian born (no) & $0.12(0.02$ to 0.26$)$ \\
\hline Insufficient physical activity (yes) & $0.16(0.01$ to 0.31$)$ \\
\hline Inadequate fruit or vegetables & $-0.03(0.14$ to 0.10$)$ \\
\hline (yes) & \\
\hline
\end{tabular}

Model 2: with K10

\begin{tabular}{ll} 
Age (55-65years) & $0.40(0.21$ to 0.55$)$ \\
\hline Age (65years and over) & $0.75(0.57$ to 0.91$)$ \\
\hline Gender (male) & $0.24(0.11$ to 0.37$)$ \\
BMI (underweight) & $0.17(0.57$ to 0.78$)$ \\
BMI (overweight) & $0.53(0.37$ to 0.70$)$ \\
BMI (obese) & $1.33(1.17$ to 1.50$)$ \\
Smoking status (smoker) & $0.48(0.25$ to 0.73$)$ \\
Hypertensive medications (yes) & $0.38(0.25$ to 0.52$)$ \\
$\begin{array}{l}\text { Diabetes history (yes) } \\
\text { Australian born (no) }\end{array}$ & $0.60(0.46$ to 0.73$)$ \\
$\begin{array}{l}\text { Insufficient physical activity (yes) } \\
\text { Inadequate fruit or vegetables }\end{array}$ & $0.12(0.03$ to 0.26$)$ \\
$\begin{array}{l}\text { (yes) } \\
\text { Psychological distress (K10 } \geq 19)\end{array}$ & $0.01(0.14$ to 0.11$)$ \\
(yes) & $0.39(0.20$ to 0.57$)$ \\
\hline
\end{tabular}

BMI, body mass index

DSM-IV and the International Statistical Classification of Diseases and Related Health Problems 10th Revision (ICD-10) Classification of Mental and Behavioural Disorders in several countries worldwide ${ }^{53-59}$ The K10 is used in all the national surveys in the WHO's World Mental Health Survey Initiative, which includes 27 countries representing all regions of the world. ${ }^{60}$

Participants were asked to rate how often, in the past 4 weeks, they felt negative emotions on 10 question items. The K10 has a five-value response option for each question-(1) all of the time, (2) most of the time, (3) some of the time, (4) a little of the time and (5) none of the time-that are scored in reverse. Thus, summed scores can range from 10 (indicating no distress) to 50 (indicating severe distress). The K10 was found to have good internal consistency (Cronbach's
ROC plot

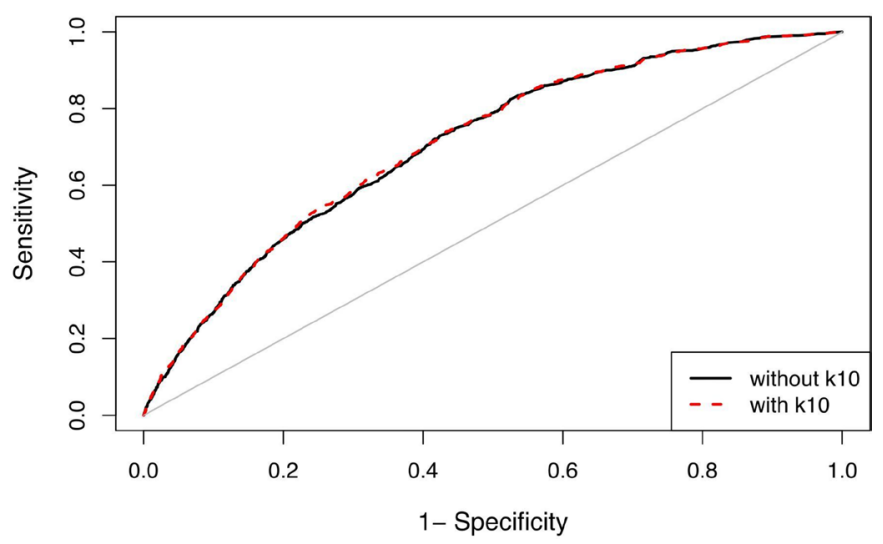

Figure 1 Receiver operating characteristics (ROC) curves based on 3-year type 2 diabetes risk predictions with and without the K10.

$\alpha$ coefficient of 0.85) based on the Australian 2004-2005 National Health Survey sample. ${ }^{61}$

\section{Statistical analyses}

First, we determined the optimal K10 cut-off in the logit used to predict diabetes at follow-up. We adopted the standard strategy of estimating different logit models using increasing values of K10 cut-offs, starting at 0 . For each logit, and corresponding value of the cut-off, we compute a goodness-of-fit measure and then pick the optimal value of the $\mathrm{K} 10$ cut-off as the one that maximises this measure. We selected the Tjur's Coefficient of Discrimination $(\mathrm{CoD})^{47}$ as our goodness-of-fit measure and used the R package 'sjstats' to calculate it. While we considered alternatives such as the McFadden and Cox-Snell Pseudo $\mathrm{R}^{2}{ }^{45}{ }^{46}$ we selected the Tjur CoD because, in addition to being closely related to $\mathrm{R}^{2}$ definitions for linear models, ${ }^{47}$ it has a very intuitive definition: it is simply the difference between the average predicted probabilities for the two classes in the logit estimation. The optimal K10 cut-off was estimated to be 19 , and therefore we created a binary

Table 3 Risk table for reclassified persons with the addition of K10 score

\begin{tabular}{|c|c|c|c|c|}
\hline Reclassification* & Events & $\begin{array}{l}\text { Non- } \\
\text { events }\end{array}$ & $\mathbf{n}$ & \% Risk (95\% Cl) \\
\hline Low->Low & 231 & 26085 & 26316 & $0.88(0.77$ to 1.00$)$ \\
\hline High->Low & 39 & 1399 & 1438 & 2.71 (1.94 to 3.69$)$ \\
\hline Low->High & 12 & 698 & 710 & 1.69 (0.88 to 2.93$)$ \\
\hline High->High & 794 & 22330 & 23124 & 3.43 (3.2 to 3.68$)$ \\
\hline Total & 1076 & 50512 & 51588 & 2.09 (1.96 to 2.21$)$ \\
\hline
\end{tabular}

$\mathrm{NRI}$ events $=(12-39) / 1076=-2.51 \%$

NRI non-events $=(1399-698) / 50512=1.39 \%$

$\mathrm{NRI}=[(12-39) / 1076]+[(1399-698) / 50512]=-1.12 \%$

$\triangle \mathrm{NB}=(-27-0.0168723043676495 \times-701) / 51588=-0.0003$

*Based on a cut-off maximising sensitivity and specificity to define high versus low risk of incident type 2 diabetes.

$\mathrm{NB}$, net benefit; NRI, net reclassification improvement. 


\begin{tabular}{|c|c|c|c|c|}
\hline Reclassification* & Events & $\begin{array}{l}\text { Non- } \\
\text { events }\end{array}$ & $\mathbf{n}$ & \% Risk (95\% Cl) \\
\hline Low->Low & 966 & 49345 & 50311 & 1.92 (1.80 to 2.04$)$ \\
\hline High->Low & 10 & 129 & 139 & 7.19 (3.50 to 12.83$)$ \\
\hline Low->High & 27 & 199 & 226 & 11.95 (8.02 to 16.9$)$ \\
\hline High->High & 73 & 839 & 912 & 8.00 (6.33 to 9.96$)$ \\
\hline Total & 1076 & 50512 & 51588 & 2.09 (1.96 to 2.21$)$ \\
\hline
\end{tabular}

NRI events $=(27-10) / 1076=1.58 \%$

$\mathrm{NRI}$ non-events $=(129-199) / 50512=-0.14 \%$

$\mathrm{NRI}=[(27-10) / 1076]+[(129-199) / 50512]=1.44 \%$

$\Delta \mathrm{NB}=(17-0.0742212045061077 \times 70) / 51588=0.0002$

*Based on a cut-off corresponding to the top 10th percentile to define high versus low risk of incident type 2 diabetes.

$\mathrm{NB}$, net benefit; NRI, net reclassification improvement.

variable which is 0 for K10 score less than or equal to 19 and 1 otherwise. For simplicity, we refer to this binary predictor as the K10 variable in the rest of analysis.

Then, we assessed performance measures for the incremental value of K10 using the area under the receiver operating characteristics (AROC) and associated 95\% CIs, net reclassification improvement (NRI) and net benefit (NB) decision analytics. ${ }^{39}$ We used sensitivity analysis techniques to assess the robustness of the decision analytics, and to test if the incremental predictive value of the K10 was dependent on size of the coefficient. We repeated the base model (model 1) replacing hypertensive medications with the K10, and assessed the incremental predictive value of hypertensive medications. We chose the hypertensive medications variable, which is commonly featured among T2D risk assessment tools, because it yielded a similar coefficient as the K10 (0.38 vs 0.39 ) in model 2.

\section{RESULTS}

Table 1 shows baseline characteristics of participants in the SEEF subsample of the 45 and Up study cohort by T2D status at follow-up, including crude incidence and corresponding age-adjusted ORs. A cut-off point of $\geq 19$ for the K10 was optimal for predicting T2D risk (sensitivity $77 \%$, specificity $53 \%$ and Positive Predictive Value (PPV) 3\%) with an OR of 1.70 (95\% CI 1.41 to 2.03, $\mathrm{P}<0.001)$. The unadjusted relative incidence of T2D was highest for: older age; male gender; Australian born; family history of diabetes; currently taking antihypertensive medications; current smoker; insufficient physical activity; do not usually eat vegetables or fruit every day; underweight, overweight and obese; and psychological distress risk groups. The incidence rate of T2D was $2.1 \%$ $(1076 / 51588)$ over an average follow-up of $3.4(\mathrm{SD}=0.95)$ years (annual incidence rate was $0.61 \%$ ).

Table 2 shows the beta coefficients for risk factors from two logistic regression models, without (model 1) and
Table 5 Risk table for reclassified persons with the addition of hypertensive medications

\begin{tabular}{|c|c|c|c|c|}
\hline Reclassification* & Events & $\begin{array}{l}\text { Non- } \\
\text { events }\end{array}$ & $\mathbf{n}$ & \% Risk (95\% Cl) \\
\hline Low->Low & 292 & 28830 & 29122 & $1.00(0.89$ to 1.12$)$ \\
\hline High->Low & 56 & 2413 & 2469 & 2.27 (1.72 to 2.94$)$ \\
\hline Low->High & 23 & 1125 & 1148 & 2.00 (1.27 to 2.99$)$ \\
\hline High->High & 705 & 18144 & 18849 & 3.74 (3.47 to 4.02$)$ \\
\hline Total & 1076 & 50512 & 51588 & 2.09 (1.96 to 2.21$)$ \\
\hline
\end{tabular}

NRI events $=(23-56) / 1076=-3.06 \%$

NRI non-events $=(2413-1125) / 50512=2.55 \%$

$\mathrm{NRI}=[(23-56) / 1076]+[(2413-1125) / 50512]=-0.52 \%$

$\triangle \mathrm{NB}=(-33-0.0193115966766661 \times-1288) / 51588=-0.0001$

*Based on a cut-off maximising sensitivity and specificity to define high versus low risk of incident type 2 diabetes.

$\mathrm{NB}$, net benefit; NRI, net reclassification improvement.

with (model 2) the K10 binary variable. Model 1 shows that all of the variables except for country of birth and diet from the AUSDRISK ${ }^{44}$ were significant predictors of incident T2D. Model 2 shows that the addition of K10, which was an independent predictor of incident T2D, resulted in no or very small changes in the beta coefficients for the remaining risk factors. Both models resulted in good performance for predicting incident T2D (AROC for model 1 and model 2 was 0.705 (0.69 to 0.72 ) and 0.708 (0.69 to 0.72 ), respectively). There was evidence of slight improvement to model 1 after fitting K10 (net change in AROC was 0.003, $\mathrm{P}=0.04$; figure 1 ).

Table 3 shows the results for reclassified persons with the addition of K10 based on a risk threshold to define low and high risk of incident T2D at which both sensitivity and specificity were maximised on the AROC (sensitivity $77 \%$, specificity $53 \%$ and positive predictive value $3 \%$ ). A small net -0.0251 decrease in high-risk classifications for those with events (NRI events) and a small net increase in low-risk classifications for those without events (NRI non-events) resulted in a negative NRI of $-1.12 \%$. The net number of true positive classifications decreased by $0.03 \%$ on a scale of $0 \%-2.1 \%$ incidence rate. This implies that 3333 additional K10 screening assessments result in one less T2D case without increasing high-risk classifications for those without incident T2D.

\section{Sensitivity analyses}

Table 4 shows the results for reclassified persons with the addition of K10 based on a top 10th percentile threshold to define high versus low risk of incident T2D. This means that an individual is classified at high risk if the risk predicted by the logit model is higher than $90 \%$. A small net increase $(1.58 \%)$ in high-risk classifications for those with events and a small net decrease $(-0.14 \%)$ in low-risk classifications for those without events resulted in a positive NRI of $1.44 \%$. The net number of true positive classifications increased by $0.02 \%$ on a scale of $0 \%-2.1 \%$ incidence rate. This implies that 5000 additional K10 
screening assessments would identify one more T2D case without increasing high-risk classifications for those without incident T2D. We simulated increases in the size of the K10 coefficient and studied the effect on the NB. Changes in the coefficient of the order of $10 \%$ were associated with changes in NB of the order of less than $0.1 \%$.

Table 5 shows the results for reclassified persons with the addition of hypertensive medications to a base model that includes the K10. A small net decrease $(-3.06 \%)$ in high-risk classifications for those with events and a small net increase $(2.55 \%)$ in low-risk classifications for those without events resulted in a small negative NRI of $-0.52 \%$. The net number of true positive classifications decreased by $-0.01 \%$ on a scale of $0 \%-2.1 \%$ incidence rate. This implies that 10000 additional screening for hypertensive medications would identify one less T2D case without increasing high-risk classifications for those without incident T2D.

\section{DISCUSSION}

In this study, we considered various statistical analyses, summary measures and graphs to assess the incremental predictive value of screening for anxiety and depression beyond current T2D risk models. First, we determined that a K10 score of $\geq 19$ was optimal for predicting approximate 3-year risk of developing T2D independent of age and gender. Second, we showed that variables from T2D risk models or tools applicable for use in routine clinical practice, including the AUSDRISK, ${ }^{44-50}$ resulted in good performance for predicting incident T2D in the 45 and Up Study cohort. Third, we showed that symptoms of anxiety and depression, assessed using an optimal K10 score of $\geq 19$, were associated with an increased risk of developing T2D independent of risk factors from current T2D risk models, consistent with previous research. ${ }^{3762-64}$ Unlike previous research, however, we showed for the first time that adding the K10 variable resulted in no incremental value beyond current T2D risk models and, in fact, resulted in a very small increase in the fraction of false positive classifications. Sensitivity analysis showed a very small positive incremental value when using a much higher decision threshold for the K10 (>90th percentile). This implies that additional screening for anxiety and depression using the K10 to current T2D risk assessment tools is unlikely to confer benefit, both to health professionals and consumers, and may lead to overtreatment for clinical prevention. However, the poor incremental predictive value of the K10 was partially explained by the baseline model as well as the small effect size that was similar compared with other risk factors. This highlights several limitations of the current approaches (AROC, NRI, NB decision analytics) for investigating incremental predictive value of novel risk factors in standard risk models.

Screening for both anxiety and depression using a broad non-specific psychological distress published evidence on the risk of developing T2D associated with anxiety remains inconsistent. ${ }^{65-67}$ Furthermore, one of these cohort studies from USA showed that the increased risk of incident diabetes associated with both clinically relevant symptoms of anxiety and depression was observed in women but not men. Thus, future research should determine the incremental predictive value of specific anxiety and depression screening tools for T2D risk assessment, and in men and women separately, if indeed a gender interaction is found.

The poor incremental predictive value of the K10 in this context has health policy implications, especially in the Australian healthcare setting for population-based screening strategies for preventing T2D. For example, the AUSDRISK tool is used in general population screening to determine eligibility for a general practitioner Health Assessment provided as part of a T2D risk evaluation for people aged 40-49 years covered by Medicare (Australia's federally funded universal healthcare scheme). In practice, patients with a 'high' (12 or more) score are eligible for the Health Assessment, and subsequent referral to allied health services to provide lifestyle programmes. The addition of the K10 to this current publicly funded T2D risk-screening programme would be unjustified, especially since the application rate of the AUSDRISK tool in general practice has reportedly been very low (approximately 14\%). ${ }^{68}$ Furthermore, the predictive value of T2D risk-screening tools for primary prevention is questionable. For instance, the AUDRISK tool has been used in diabetes prevention trials in Australia (including the Greater Green Triangle Diabetes Prevention Project, ${ }^{69}$ Melbourne Diabetes Prevention Study ${ }^{70}$ Sydney Diabetes Prevention Program ${ }^{71}$ and Victorian Life! Program ${ }^{72}$ ) targeting high-risk individuals identified using the AUSDRISK, ${ }^{44}$ none of which have demonstrated effectiveness for reducing the incidence of T2D. This highlights the importance of risk stratification beyond those identified using the AUSDRISK score of 12 or more ${ }^{44}$ for primary prevention of T2D.

Despite the poor incremental predictive value of the K10, it remained a predictor of developing T2D after correction for all of the other predictors. This suggests that screening for anxiety and depression would identify a large group of individuals otherwise not apparent with current T2D risk assessment tools, which might be clinically important for treatment decision making for the management of psychological comorbidity. Previous systematic reviews of RCTs have shown that exercise (an integral component of lifestyle intervention) is effective for improving both depression score (standardised mean difference was -0.82 (95\% CI -1.12 to -0.51$)$ ) and HbA1c level (weighted mean difference was $-0.67 \%$ (95\% CI -0.84 to -0.49$)),{ }^{73} 74$ and the size of these effects are substantially larger than what we found for collaborative care for depression. ${ }^{75}$ Overall, this evidence suggests that lifestyle intervention integrated within the collaborative care model would be most effective for preventing T2D in people with comorbid anxiety and depression. 
Strengths of this study include the recruitment of a large (over 250000 participants) population-based sample at baseline, ${ }^{41}$ and the high (over 60\%) response rate achieved in the subsample at follow-up. ${ }^{76}$ Study weaknesses include the low incidence of T2D observed in the cohort, reliance on self-report measures, low (less than $18 \%$ ) response rate achieved at baseline ${ }^{41}$ residual confounding and misclassification of variables potentially resulting in bias. Further evidence from prospective cohort studies is needed to confirm the generalisability of these findings and the applicability of specific screening tools for anxiety and depression in specific healthcare settings.

In conclusion, anxiety and depressing screening with the K10 adds no meaningful incremental value beyond current T2D risk models applicable for use in routine clinical practice. Additional screening for anxiety and depression using the K10 is unlikely to confer benefit, both to health professionals and consumers and may lead to overtreatment for clinical prevention. However, since the lack of incremental predictive value of the K10 was partially explained by the baseline model as well as the small effect size, our main finding should be interpreted with caution. The clinical importance of anxiety and depression screening for preventing T2D in primary healthcare requires further consideration and research.

Contributors EA is guarantor of the paper, taking responsibility for the integrity of the work as a whole, from inception to publication of article. All authors conceived and designed the study. EA was responsible for drafting the manuscript. SGP and FG were responsible for data analysis and interpretation. All authors contributed to drafting the work for important intellectual content, and approved the final completed article.

Funding This research received no specific grant from any funding agency in the public, commercial or not-for-profit sectors.

Competing interests None declared.

Patient consent Obtained.

Ethics approval The analysis presented in this paper belongs to a broader research programme that was granted ethics approval by the NSW Population and Health Services Research Ethics Committee (reference: HREC/15/CIPHS/4).

Provenance and peer review Not commissioned; externally peer reviewed.

Data sharing statement The 45 and Up Study is ready and available to Australia's researchers. Advice and instructions is available at https://www.saxinstitute.org. au/for-researchers/our-research/. The dataset is not available from the Dryad repository.

Open Access This is an Open Access article distributed in accordance with the Creative Commons Attribution Non Commercial (CC BY-NC 4.0) license, which permits others to distribute, remix, adapt, build upon this work non-commercially, and license their derivative works on different terms, provided the original work is properly cited and the use is non-commercial. See: http://creativecommons.org/ licenses/by-nc/4.0/

(C) Article author(s) (or their employer(s) unless otherwise stated in the text of the article) 2018. All rights reserved. No commercial use is permitted unless otherwise expressly granted.

\section{REFERENCES}

1. International Diabetes Federation. IDF diabetes Atlas. 7th edn. Belgium: International Diabetes Federation, 2015.

2. Murray CJ, Vos T, Lozano R, et al. Disability-adjusted life years (DALYs) for 291 diseases and injuries in 21 regions, 1990-2010: a systematic analysis for the global burden of disease study 2010. Lancet 2012;380:2197-223.

3. Australian Institute of Health and Welfare. Diabetes: Australian facts 2008. Canberra: Australian Institute of Health and Welfare, 2008. Cat. no. CVD 40.

4. Genuth S, Alberti KG, Bennett P, et al. Follow-up report on the diagnosis of diabetes mellitus. Diabetes Care 2003;26:3160-7.

5. Dunstan DW, Zimmet PZ, Welborn TA, et al. The rising prevalence of diabetes and impaired glucose tolerance: the Australian Diabetes, Obesity and Lifestyle Study. Diabetes Care 2002;25:829-34.

6. Cowie CC, Rust KF, Ford ES, et al. Full accounting of diabetes and pre-diabetes in the U.S. population in 1988-1994 and 2005-2006. Diabetes Care 2009;32:287-94.

7. International Diabetes Federation. IDF diabetes Atlas. 6th edn. Belgium: International Diabetes Federation, 2013.

8. Danaei G, Finucane MM, Lu Y, et al. National, regional, and global trends in fasting plasma glucose and diabetes prevalence since 1980: systematic analysis of health examination surveys and epidemiological studies with 370 country-years and 2.7 million participants. Lancet 2011;378:31-40.

9. Atlantis $\mathrm{E}$, Lange $\mathrm{K}$, Wittert GA, et al. Chronic disease trends due to excess body weight in Australia. Obes Rev 2009;10:543-53.

10. Magliano DJ, Barr EL, Zimmet PZ, et al. Glucose indices, health behaviors, and incidence of diabetes in Australia: the Australian Diabetes, obesity and lifestyle study. Diabetes Care 2008;31:267-72.

11. Alberti KG, Zimmet $P$, Shaw J, et al. International Diabetes Federation: a consensus on Type 2 diabetes prevention. Diabet Med 2007;24:451-63.

12. Yoda M, Inaba M, Okuno S, et al. Poor muscle quality as a predictor of high mortality independent of diabetes in hemodialysis patients. Biomed Pharmacother 2012;66:266-70.

13. Tuomilehto J, Lindström J. The major diabetes prevention trials. Curr Diab Rep 2003;3:115-22.

14. Atlantis E. Excess burden of type 1 and type 2 diabetes due to psychopathology. J Affect Disord 2012;142(Suppl):S36-S41.

15. Lin EH, Von Korff M, Alonso J, et al. Mental disorders among persons with diabetes--results from the World Mental Health Surveys. $J$ Psychosom Res 2008;65:571-80.

16. Moussavi S, Chatterji S, Verdes E, et al. Depression, chronic diseases, and decrements in health: results from the World Health Surveys. Lancet 2007;370:851-8.

17. Lin EH, Katon W, Von Korff M, et al. Relationship of depression and diabetes self-care, medication adherence, and preventive care. Diabetes Care 2004;27:2154-60.

18. Atlantis E, Goldney RD, Eckert KA, et al. Trends in health-related quality of life and health service use associated with comorbid diabetes and major depression in South Australia, 1998-2008. Soc Psychiatry Psychiatr Epidemiol 2012;47:871-7.

19. Lin EH, Rutter CM, Katon W, et al. Depression and advanced complications of diabetes: a prospective cohort study. Diabetes Care 2010;33:264-9.

20. Park M, Katon WJ, Wolf FM, et al. Depression and risk of mortality in individuals with diabetes: a meta-analysis and systematic review. Gen Hosp Psychiatry 2013;35:217-25.

21. Molosankwe I, Patel A, José Gagliardino J, et al. Economic aspects of the association between diabetes and depression: a systematic review. J Affect Disord 2012;142(Suppl):S42-S55.

22. Swardfager W, Yang P, Herrmann N, et al. Depressive symptoms predict non-completion of a structured exercise intervention for people with Type 2 diabetes. Diabet Med 2016;33:529-36.

23. Swardfager W, Herrmann N, Marzolini S, et al. Major depressive disorder predicts completion, adherence, and outcomes in cardiac rehabilitation: a prospective cohort study of 195 patients with coronary artery disease. J Clin Psychiatry 2011;72:1181-8.

24. Jagielski AC, Brown A, Hosseini-Araghi M, et al. The association between adiposity, mental well-being, and quality of life in extreme obesity. PLoS One 2014;9:e92859.

25. Somerville R, McKenzie K, Eslami S, et al. Poor mental health in severely obese patients is not explained by the presence of comorbidities. Clin Obes 2015;5:12-21.

26. Hay P, Girosi F, Mond J, et al. Prevalence and sociodemographic correlates of DSM- 5 eating disorders in the Australian population. J Eat Disord 2015;3:19.

27. Young-Hyman DL, Davis CL. Disordered eating behavior in individuals with diabetes: importance of context, evaluation, and classification. Diabetes Care 2010;33:683-9.

28. Hudson JI, Hiripi E, Pope HG, et al. The prevalence and correlates of eating disorders in the national comorbidity survey replication. Biol Psychiatry 2007;61:348-58. 
29. Legenbauer T, De Zwaan M, Benecke A, et al. Depression and anxiety: their predictive function for weight loss in obese individuals. Obes Facts 2009;2:227-34.

30. Brunault $\mathrm{P}$, Jacobi $\mathrm{D}$, Miknius $\mathrm{V}$, et al. High preoperative depression, phobic anxiety, and binge eating scores and low medium-term weight loss in sleeve gastrectomy obese patients: a preliminary cohort study. Psychosomatics 2012;53:363-70.

31. Gorin AA, Niemeier HM, Hogan P, et al. Binge eating and weight loss outcomes in overweight and obese individuals with type 2 diabetes: results from the look AHEAD trial. Arch Gen Psychiatry 2008;65:1447-55.

32. Araghi $\mathrm{MH}$, Jagielski $\mathrm{A}$, Neira I, et al. The complex associations among sleep quality, anxiety-depression, and quality of life in patients with extreme obesity. Sleep 2013;36:1859-65.

33. Atlantis E, Goldney RD, Eckert KA, et al. Trends in health-related quality of life and health service use associated with body mass index and comorbid major depression in South Australia, 1998-2008. Qual Life Res 2012;21:1695-704.

34. Campayo A, de Jonge P, Roy JF, et al. Depressive disorder and incident diabetes mellitus: the effect of characteristics of depression. Am J Psychiatry 2010;167:580-8.

35. Mezuk B, Eaton WW, Albrecht S, et al. Depression and type 2 diabetes over the lifespan: a meta-analysis. Diabetes Care 2008;31:2383-90.

36. Atlantis E, Browning C, Sims J, et al. Diabetes incidence associated with depression and antidepressants in the Melbourne Longitudinal Studies on Healthy Ageing (MELSHA). Int J Geriatr Psychiatry 2010;25:688-96.

37. Atlantis E, Vogelzangs $\mathrm{N}$, Cashman $\mathrm{K}$, et al. Common mental disorders associated with 2-year diabetes incidence: the Netherlands Study of Depression and Anxiety (NESDA). J Affect Disord 2012;142(Suppl):S30-35.

38. Atlantis E, Fahey P, Martin S, et al. Predictive value of serum testosterone for type 2 diabetes risk assessment in men. BMC Endocr Disord 2016;16:26.

39. Gillies CL, Lambert PC, Abrams KR, et al. Different strategies for screening and prevention of type 2 diabetes in adults: cost effectiveness analysis. BMJ 2008;336:1180-5.

40. Noble D, Mathur R, Dent T, et al. Risk models and scores for type 2 diabetes: systematic review. BMJ 2011;343:d7163.

41. Banks E, Redman S, Jorm L, et al. Cohort profile: the 45 and up study. Int J Epidemiol 2008;37:941-7.

42. Mealing NM, Banks E, Jorm LR, et al. Investigation of relative risk estimates from studies of the same population with contrasting response rates and designs. BMC Med Res Methodol 2010;10:26.

43. Comino EJ, Tran DT, Haas M, et al. Validating self-report of diabetes use by participants in the 45 and up study: a record linkage study. BMC Health Serv Res 2013;13:481.

44. Chen L, Magliano DJ, Balkau B, et al. AUSDRISK: an Australian type 2 diabetes risk assessment tool based on demographic, lifestyle and simple anthropometric measures. Med J Aust 2010;192:197-202.

45. Schmidt MI, Duncan BB, Bang $\mathrm{H}$, et al. Identifying individuals at high risk for diabetes: The Atherosclerosis risk in communities study. Diabetes Care 2005;28:2013-8.

46. Rahman M, Simmons RK, Harding AH, et al. A simple risk score identifies individuals at high risk of developing Type 2 diabetes: a prospective cohort study. Fam Pract 2008;25:191-6.

47. Lindström J, Tuomilehto J. The diabetes risk score: a practical tool to predict type 2 diabetes risk. Diabetes Care 2003;26:725-31.

48. Wilson PW, Meigs JB, Sullivan L, et al. Prediction of incident diabetes mellitus in middle-aged adults: the Framingham offspring study. Arch Intern Med 2007;167:1068-74.

49. Stern MP, Williams K, Haffner SM, et al. Identification of persons at high risk for type 2 diabetes mellitus: do we need the oral glucose tolerance test? Ann Intern Med 2002;136:575-81.

50. Hippisley-Cox J, Coupland C, Robson J, et al. Predicting risk of type 2 diabetes in England and Wales: prospective derivation and validation of QDScore. BMJ 2009;338:b880.

51. The baseline questionnaire. https://www.saxinstitute.org.au/ourwork/45-up\%20study/questionnaires/ (accessed 15 Dec 2016).

52. Kessler RC, Andrews G, Colpe LJ, et al. Short screening scales to monitor population prevalences and trends in non-specific psychological distress. Psychol Med 2002;32:959-76.
53. Bougie E, Arim RG, Kohen DE, et al. Validation of the 10-item Kessler Psychological distress scale (K10) in the 2012 aboriginal peoples survey. Health Rep 2016;27:3-10.

54. Andrews G, Slade T. Interpreting scores on the Kessler psychological distress scale (K10). Aust N Z J Public Health 2001;25:494-7.

55. Furukawa TA, Kessler RC, Slade T, et al. The performance of the K6 and K10 screening scales for psychological distress in the Australian national survey of mental health and well-being. Psychol Med 2003;33:357-62.

56. Cairney J, Veldhuizen S, Wade TJ, et al. Evaluation of 2 measures of psychological distress as screeners for depression in the general population. Can J Psychiatry 2007;52:111-20.

57. Oakley Browne MA, Wells JE, Scott KM, et al. The Kessler psychological distress scale in te rau hinengaro: the New Zealand mental health survey. Aust N Z J Psychiatry 2010;44:314-22.

58. Fassaert T, De Wit MA, Tuinebreijer WC, et al. Psychometric properties of an interviewer-administered version of the Kessler Psychological Distress scale (K10) among Dutch, Moroccan and Turkish respondents. Int J Methods Psychiatr Res 2009;18:159-68.

59. Furukawa TA, Kawakami N, Saitoh M, et al. The performance of the Japanese version of the K6 and K10 in the world mental health survey Japan. Int J Methods Psychiatr Res 2008;17:152-8.

60. School AcHM. The world mental health survey initiative. https://www. hcp.med.harvard.edu/wmh/index.php

61. Atlantis E, Ball K, et al. Association between weight perception and psychological distress. Int J Obes 2008;32:715-21.

62. Ding D, Chong S, Jalaludin B, et al. Risk factors of incident type 2-diabetes mellitus over a 3-year follow-up: results from a large Australian sample. Diabetes Res Clin Pract 2015;108:306-15.

63. Virtanen M, Ferrie JE, Tabak AG, et al. Psychological distress and incidence of type 2 diabetes in high-risk and low-risk populations: the Whitehall II Cohort Study. Diabetes Care 2014;37:2091-7.

64. Twig G, Gerstein HC, Fruchter E, et al. Self-perceived emotional distress and diabetes risk among young men. Am J Prev Med 2016:50:737-45.

65. Chien IC, Lin $\mathrm{CH}$. Increased risk of diabetes in patients with anxiety disorders: A population-based study. J Psychosom Res 2016;86:47-52.

66. Edwards LE, Mezuk B. Anxiety and risk of type 2 diabetes: evidence from the Baltimore epidemiologic catchment area study. $J$ Psychosom Res 2012;73:418-23.

67. Demmer RT, Gelb S, Suglia SF, et al. Sex differences in the association between depression, anxiety, and type 2 diabetes mellitus. Psychosom Med 2015;77:467-77.

68. Wong KC, Brown AM, Li SC, et al. AUSDRISK - application in general practice. Aust Fam Physician 2011;40:524-6.

69. Laatikainen T, Dunbar JA, Chapman A, et al. Prevention of Type 2 diabetes by lifestyle intervention in an Australian primary health care setting: Greater Green Triangle (GGT) diabetes prevention project. BMC Public Health 2007;7:1-7.

70. Dunbar JA, Hernan AL, Janus ED, et al. Challenges of diabetes prevention in the real world: results and lessons from the Melbourne Diabetes Prevention Study. BMJ Open Diabetes Res Care 2015;3:e000131.

71. Colagiuri S, Vita P, Cardona-Morrell M, et al. The Sydney diabetes prevention program: a community-based translational study. BMC Public Health 2010;10:1-7.

72. Dunbar JA, Jayawardena A, Johnson G, et al. Scaling up diabetes prevention in Victoria, Australia: policy development, implementation, and evaluation. Diabetes Care 2014;37:934-42.

73. Rimer J, Dwan K, Lawlor DA, et al. Exercise for depression. Cochrane Database Syst Rev 2012:CD004366.

74. Umpierre D, Ribeiro PA, Kramer CK, et al. Physical activity advice only or structured exercise training and association with $\mathrm{HbA} 1 \mathrm{c}$ levels in type 2 diabetes: a systematic review and meta-analysis. JAMA 2011;305:1790-9.

75. Atlantis E, Fahey P, Foster J, et al. Collaborative care for comorbid depression and diabetes: a systematic review and meta-analysis. BMJ Open 2014;4:e004706.

76. Bauman A, Phongsavan P, Cowle A, et al. Maximising follow-up participation rates in a large scale 45 and up study in Australia. Emerg Themes Epidemiol 2016;13:6. 